\title{
BMJ Open Lay community perceptions and treatment options for hypertension in rural northern Ghana: a qualitative analysis
}

\author{
Gertrude Nsorma Nyaaba, ${ }^{1,2}$ Lina Masana, ${ }^{2,3}$ Ama de-Graft Aikins, ${ }^{4}$ \\ Karien Stronks, ${ }^{1}$ Charles Agyemang ${ }^{1}$
}

To cite: Nyaaba GN, Masana L, Aikins Ad-G, et al. Lay community perceptions and treatment options for hypertension in rural northern Ghana: a qualitative analysis. BMJ Open 2018;8:e023451. doi:10.1136/ bmjopen-2018-023451

- Prepublication history and additional material for this paper are available online. To view these files, please visit the journal online (http://dx.doi org/10.1136/bmjopen-2018023451).

Received 9 April 2018 Revised 28 September 2018 Accepted 9 October 2018

Check for updates

(C) Author(s) (or their employer(s)) 2018. Re-use permitted under CC BY-NC. No commercial re-use. See rights and permissions. Published by BMJ.

${ }^{1}$ Department of Public Health, Amsterdam Public Health (APH) Research Institute, Amsterdam University Medical Centers, University of Amsterdam, Amsterdam, The Netherlands ${ }^{2}$ Barcelona Institute for Global Health (ISGlobal), University of Barcelona, Barcelona, Spain

${ }^{3}$ Medical Anthropology Research Centre, University of Rovira i

Virgili, Tarragona, Spain

${ }^{4}$ Regional Institute for Population Studies, University of Ghana,

Legon, Ghana

Correspondence to Gertrude Nsorma Nyaaba; g.n.nyaaba@amc.uva.nl

\section{ABSTRACT}

Objective Adherence to hypertension treatment is a major public health challenge for low and middle-income countries particularly in sub-Saharan Africa. One potential reason could be the discordance between lay and medical explanatory models of hypertension and its treatment. Understanding community perceptions and practices may contribute to improving hypertension control as they present insights into psychosocial and cultural factors that shape individual behaviour. We explore community perceptions regarding hypertension and its treatment in rural northern Ghana and how they differ from medical understanding.

Design This was a qualitative study using semi-structured interviews and focus group discussions to collect data, which were analysed using a thematic approach.

Setting A multisite study conducted in four rural communities in two regions of northern Ghana.

Participants We conducted 16 semi-structured interviews and eight focus group discussions with community leaders and members, respectively.

Results Three major themes were identified: community perceptions, treatment options and community support for people with hypertension. Community perceptions about hypertension include hypertension perceived as excess blood in the body and associated with spiritual or witchcraft attacks. Traditional medicine is perceived to cure hypertension completely with concurrent use of biomedical and traditional medicines encouraged in rural communities. Community members did not consider themselves at risk of developing hypertension and reported having inadequate information on how to provide social support for hypertensive community members, which they attributed to low literacy and poverty.

Conclusion There is a substantial mismatch between communities' perceptions and medical understanding of hypertension and its treatment. These perceptions partly result from structural factors and social norms shaped by collective processes and traditions that shape lay beliefs and influence individual health behaviour. Socioeconomic factors also thwart access to information and contribute to inadequate social support for persons with hypertension. These findings highlight the need for a public health approach to hypertension control targeting families and communities.

\section{BACKGROUND}

Hypertension (HTN) is a major risk factor for cardiovascular diseases (CVDs) and is

\section{Strengths and limitations of this study}

This study represents the first of its kind in Ghana to explore, in depth, community explanatory models regarding hypertension and its treatment in rural northern Ghana.

- The study collected data from a limited set of participants in four purposively sampled communities in northern Ghana in two local languages that may not reflect the views of other communities or ethnic groups in northern Ghana.

- The study did not have an equal representation of male and female community leaders in the semi-structured interviews and as such may not present a comprehensive overview of female community leaders insights on the topic.

- The study focused specifically on community members who had some general and/or in-depth experience with persons with hypertension and thus allowed us to identify community perceptions about hypertension and its treatment options, explore the processes that contribute to shaping these perceptions surrounding hypertension and how they differ from current medical knowledge.

- To ensure that the results were representative, we used the semi-structured interviews with community leaders to triangulate and explore in-depth the data that were collected in the focus group discussions.

frequently comorbid with other non-communicable diseases (NCDs). ${ }^{12}$ It rarely causes any symptoms, but it is an indicator for needed behavioural changes. ${ }^{3}$ Evidence shows that adherence to HTN treatment improves control and reduces CVD risk. ${ }^{4-6}$ However, HTN treatment and control remain a difficult public health problem despite increased HTN prevalence particularly in sub-Saharan Africa (SSA). ${ }^{278}$ A possible explanation could be the difference between people's lay beliefs and medical understanding of HTN. Identifying people's lay beliefs surrounding HTN and understanding the underlying factors that shape such beliefs is therefore crucial to understanding the norms and factors 
that influence individuals' actions towards HTN control. This is vital for improving HTN control and preventing HTN-related complications particularly in rural communities and communities with low socioeconomic status. Studies have shown that such communities are more vulnerable to NCDs and are further entrenched into poverty because of the exorbitant costs associated with seeking healthcare for chronic diseases. ${ }^{910}$

Kleinman in his lay explanatory models (EMs) proposes that there can be different notions of health and diseases by different groups of people. He argues that people's understanding of their illness often differ from biomedical understanding of diseases, and these differences could affect treatment outcomes. ${ }^{11}$ Kleinman identifies the definition of the illness, its perceived causes, symptoms, duration, severity, expected consequences, appropriate treatment and anticipated outcomes as the eight key pillars of a comprehensive EM. ${ }^{11}$ Several studies have shown that patient's EMs differ from biomedical EMs. ${ }^{10}{ }^{12-14}$ In particular, studies in the USA and UK have stressed that traditional and cultural beliefs and practices have an influence on perceptions regarding HTN among people of African descent. In SSA, a study, conducted in Zambia among adult rural participants reported a preference for using alternative medicines and herbs for BP treatment, ${ }^{15}$ while another study in Nigeria found that while social support could contribute to compliance to HTN treatment, ${ }^{16}$ even among people of the same ethnicity, there could be varied beliefs about HTN. These studies suggest that communities' perceptions regarding illness influence how individuals understand and perceive their illness and could subsequently influence health outcomes for HTN and for other chronic diseases. Gaining insights into communities' perceptions on HTN and the underlying factors shaping such perceptions could facilitate an understanding of how communities conceptualise and construct meanings for specific illnesses and treatment options, which is important for designing innovative and culturally acceptable health interventions for prevention and control of HTN and other NCDs.

In Ghana as in most SSA countries, HTN is the second most common cause of outpatient morbidity. ${ }^{1}$ Public health campaigns have been the main source of public awareness, but these have generated low awareness even among health workers and resulted in little behaviour change. ${ }^{517}$ A recent study found a $22 \%$ age-standardised prevalence of HTN in rural Ghana, and $85 \%$ of study participants in rural Ghana with severe HTN were untreated. ${ }^{8}$ Another study in three poor urban communities in Accra showed that, despite a $28.3 \%$ prevalence of HTN, only $7.4 \%$ were aware of their condition, $4 \%$ were on antihypertensive medicines and only $3.5 \%$ had their blood pressure (BP) adequately controlled. ${ }^{18}$ This study found limited knowledge of the risk factors, poor access to medicines and healthcare and poor medication adherence as key reasons for the poor control of HTN. ${ }^{18}$ It is unclear if these reasons for the poor control in urban Ghana are applicable in rural Ghana and the extent to which community perceptions and practices could explain patient behaviour and practices towards HTN treatment and control.

Most research studies on HTN have been conducted in urban Ghana among people with HTN and health professionals and have used mainly quantitative tools. ${ }^{5}$ 19-22 To the best of our knowledge, no study has explored community perceptions regarding HTN in the rural and lower socioeconomic communities of northern Ghana using a qualitative approach. HTN is regularly among the top five causes of morbidity in northern Ghana with a study reporting a $19.3 \%$ high $\mathrm{BP}$ prevalence in a rural community in northern Ghana. ${ }^{23-25}$ Northern Ghana is largely rural has the lowest literacy rates, high levels of poverty, malnutrition, high burden of infectious diseases, limited access to healthcare services and acute shortages of health professionals. ${ }^{24-27}$ Cultural and traditional activities also affect social determinants of health such as education and household decision-making power with some cultural practices deeply rooted in age-long spiritual beliefs. ${ }^{24}$ This blend of structural and cultural factors contribute to shaping community members' understanding and conceptualisation of HTN and treatment options and influence health behaviour and practices. Indeed, previous studies conducted in northern Ghana show that community perceptions and practices differ from biomedical explanations for childhood illness ${ }^{28}$ and childhood mortality ${ }^{29}$ and for infectious diseases such as malaria ${ }^{30}$ and filariasis, ${ }^{31}$ yet scant evidence exists on if community perceptions and practices for HTN differ from biomedical practices and the factors that contribute to shaping such perceptions and practices towards HTN. Janzen identifies this group of people, that is, family and community members in African societies, as the 'therapy managing group' who take responsibility during illness by playing a 'brokerage function' between the patient and the specialist. ${ }^{32}$ Because community and family members live, work with and serve as the 'therapy managing group ${ }^{32}$ for people with HTN, particularly in rural African communities, they play key roles in influencing individual health behaviour and practices towards HTN treatment and control. Using semistructured interviews and focus group discussions (FGDs) with non-hypertensive community members and leaders, we explored communities' casual theories of HTN, its treatment options and social support for people with HTN to understand how they could influence treatment and control of HTN in rural Ghana. We further explored underlying factors shaping communities' lay beliefs and identify commonalities and differences between lay perceptions and biomedical models for HTN using Kleinman's concept.

\section{METHODOLOGY}

\section{Study setting}

Northern Ghana is made up of three administrative regions of Ghana (Northern, Upper East and Upper West Regions) that are predominantly rural and agrarian 
with widely dispersed settlements. The area has the highest poverty profile and the lowest literacy rates in the country. ${ }^{24} 25$ This study was conducted in the Northern Region (NR) and Upper East Region (UER) of northern Ghana. Northern Region and Upper East Region were purposively selected because they are the largest and most populated of the three regions, and the only tertiary health referral hospital for northern Ghana is located in Tamale, NR. The Mole-Dagbon is the main ethnic group in northern Ghana with Dagbani as the main spoken language in NR, and in the UER, Gurune (Frafra), Kassem, Nankani, Buili, Kussal, Mampruli and Bisa are the main spoken languages. Islam is the main religion in NR followed by traditional religion, which together, are practised by over $75 \%$ of the population. ${ }^{25}$ In UER, traditional religion is the main religion followed by Christianity, which together, are practised by over $70 \%$ of the population. ${ }^{24}$

\section{Participant and public involvement}

Study participants were not involved in the setting of the research questions or study design, but we engaged some study participants in recruiting community members who met our selection criteria for the discussions. Because of the iterative nature of the study, topic guides were broadened to explore in-depth, emerging themes. Furthermore, community leaders will be engaged in dissemination of the study findings.

\section{Study design}

This study is part of a larger multisite study to explore the factors for the low rates of HTN control in Ghana. We used grounded theory ${ }^{33} 34$ to generate initial study questions on the factors for the low rates of HTN control among sub-Saharan Africans, which guided the overall study design and data collection. We used Kleinman's EM specifically to investigate how communities construct meaning for $\mathrm{HTN}^{11}$ and how they differ from biomedical models of HTN. We further explored the sociocultural realities and structural factors that influence how communities experience and construct meaning for HTN. The study design, data collection, analysis and reporting were conducted in accordance with the consolidated criteria for reporting qualitative research as shown in online supplementary file 1 . We collected cross-sectional qualitative data from a total of 96 non-hypertensive community members and leaders in four communities using semi-structured interviews and FGDs between March and June 2017. We used FGDs with community members to gain broader insights and understanding of communities' social views regarding causes of HTN, treatment options and the role of social support in HTN management. We further explored these themes in depth and explored the generalisability of these perceptions as expressed in the FGDs using semistructured interviews with community leaders. We sought written, thumbprinted and verbal consent from each participant prior to collecting data in the form of digitally recorded audio files. The research team had no prior contact with study participants.

\section{FGDs with community members}

In each of the two regions, we conducted four FGDs with non-hypertensive community members in the regional capital and in a district town where patients access healthcare for HTN. Eight to 11 community members recruited in collaboration with a key informant (usually, the assemblyman) constituted each FGD. FGDs were grouped by sex because previous research suggests that due to the sociocultural context, women may not actively participate in discussions in the presence of men. ${ }^{35}$ Participants were recruited if they had lived within the community for at least 5 years, had not been previously diagnosed as hypertensive and knew someone diagnosed with HTN within their social network. Participants were invited by the assembly member in the company of the first author. Participants received both an information sheet and verbal information about the purpose of the research from the first author. Participants met at a community meeting point on a given day at a scheduled time. We invited 12 community members for each FGD with discussions starting with a minimum of six members and others joining in as the discussions progressed. Standard guidelines for conducting FGDs indicate that groups should consist of 6-10 participants ${ }^{36}$ because groups of more than eight are difficult to control. ${ }^{38}$ Since the first author had personally met and provided study information to invited participants, she identified and engaged late-coming participants to join the discussions. Digital recording was paused when late-coming participants arrived in order to allow for introductions and discussions resumed. Since participants already knew each other, the first author did not observe any difficulties for latecomers joining the discussion. At least one invited community member did not attend the discussions at the scheduled time for unknown reasons. Discussion time ranged between 40 minutes and 76 minutes. Trained research assistants (RAs) with at least 2 years' experience collecting qualitative data moderated the discussions in the local languages (Dagbani and Gurune) in each region using a topic guide developed by the authors based on HTN and NCD literature in Africa and their research experience. The first author, who understands the local languages, observed all the discussions and participated by probing or following up on responses that required clarification or further explanation and taking notes. The first author, who has extensive experience collecting and analysing qualitative data, politely excused any curious bystanders during the discussions to ensure privacy in line with standard guidelines for conducting FGDs.

\section{Semi-structured interviews with community leaders}

We identified and invited eight active community leaders in collaboration with senior staff health professionals at 
the regional and district health centres for semi-structured interviews in each region. Senior health professionals contacted community leaders via phone, and on the agreed dates, the first author together with a senior health professional met each community leader for introductions and to schedule date and time for the interview. Participants received both an information sheet and verbal information about the study, and interviews were conducted at their homes. No identified leader refused to participate in the study. We tried to involve as many female community leaders as possible, but we could only reach two female leaders in the districts we selected in the NR and one female leader in UER because most of the active community leaders were male. Selected community leaders included subchiefs, magagyas (female leaders of community women) and assembly members. Trained RAs conducted the interviews in the local languages using a topic guide developed by the authors with interview time ranging from 30 minutes to 65 minutes per interview in the presence of the first author. In cases where community leaders could speak English, the first author conducted the interviews personally.

\section{Data analysis}

Data analysis was conducted after all interviews had been conducted, transcribed and quality checked. Two RAs who are natives of the regions transcribed the interviews verbatim from the local languages directly into English. The first author reviewed all transcripts. Because majority of study participants could not read and/nor write in English or the local language, transcripts were not returned to participants for cross-checking.

Using a thematic approach to data analysis, the coding framework generated by the first author involved initial preidentified codes derived from previous literature on HTN, diabetes and chronic disease in Ghana. ${ }^{12} 132239$ Open-ended inductive codes were also generated based on the practical research experience of the authors and the socioeconomic and cultural contexts of the study area. ${ }^{2425} 27$ Codes were reviewed with coauthors and active data coding of transcripts began. The first author reviewed, coded and analysed all transcripts in constant comparison in QRS NVivo 11 pro. Emphasis was placed on how sociocultural and structural factors shaped communities' EMs regarding HTN and its treatment and the practicalities of providing social support for persons with HTN. We explored in depth the patterns and linkages between quotes, codes, themes, existing literature and the conceptual framework to assess content and areas of convergence and divergence between lay and biomedical EMs of HTN and its management. Quotations were grouped under codes and subcodes based on identified themes. Subcodes were then recoded by first author after discussions with coauthors (LM, KS and CA) under three broader themes, namely, community views, treatment options and social support (table 1).

Themes were then explored to identify divergence or similarities to biomedical models for HTN, its treatment and management in Ghana and elsewhere.

\section{RESULTS}

We present the results under three broad themes and subthemes (table 1) and provide characteristics of study participants in table 2 .

\section{Community views about HTN}

Community members reported an increasing number of community members having HTN. HTN was referred to in the local language as an 'excess of blood' in the body, related to the heart or chest or due to irregularities in the flow of blood to the body. In NR, HTN is referred to as Zhiduli or Ziemdoro (blood is gone high or blood sickness) or Nyomugli (chest problems), while in the UER, HTN is described as Sunsua ba (heart or anger sickness), Zeemzore ba-a or Zeemdoyah ba-a (blood is plenty or blood is high sickness) and Susu folgre (heart burns). Community members elaborated that this was how HTN was described to them in the local languages by health professionals. This was confirmed in the interviews with community leaders. Some community members in UER held the view that HTN was communicable though contact with the

\begin{tabular}{ll}
\hline Table 1 Themes and definitions \\
\hline Themes & Description \\
\hline $\begin{array}{l}\text { Community views about } \\
\text { hypertension (HTN) }\end{array}$ & $\begin{array}{l}\text { This theme considers all community views and perceptions regarding HTN. It explores the definition of HTN } \\
\text { in the local language and its meaning, community perceptions of persons with HTN, sources of information, } \\
\text { causes of HTN and current occurrence comparison with occurrence in the past. }\end{array}$ \\
Current treatment options & $\begin{array}{l}\text { This theme explores community views on available treatment options for people living with HTN. It explores } \\
\text { the use of traditional and alternative medicines and biomedical treatment options for HTN, explores the } \\
\text { concurrent use of these treatment methods, perceptions regarding the effectiveness and uses of each } \\
\text { treatment option and explores the reasons for non-adherence to antihypertensive medication. In this theme, } \\
\text { traditional medicine is defined to include the use of herbal medicines, spiritual healing and herbal remedies. } \\
\text { Clinical care is defined to include the use of biomedical care and adherence to antihypertensive medication } \\
\text { and behaviour changes. }\end{array}$ \\
\hline $\begin{array}{l}\text { Community support for people } \\
\text { living with HTN }\end{array}$ & $\begin{array}{l}\text { This theme relates to the community members' views on the role of social support for persons living with } \\
\text { hypertension, what community members perceive as social support factors that influence social support for } \\
\text { persons with HTN and recommendations on how community and family members can support persons with } \\
\text { HTN to adhere to treatment. }\end{array}$ \\
\hline
\end{tabular}




\begin{tabular}{|c|c|c|c|c|c|c|c|c|}
\hline \multicolumn{9}{|c|}{ A. Characteristics of focus group discussions (FGD) with community members $(C M)(n=80)$} \\
\hline ID & No. of participants & Sex & Age (years) & $\begin{array}{l}\text { Educational } \\
\text { status }\end{array}$ & $\begin{array}{l}\text { Known } \\
\text { someone } \\
\text { diagnosed with } \\
\text { HTN/NCD }\end{array}$ & Duration (mm) & \multicolumn{2}{|l|}{ Location } \\
\hline $\begin{array}{l}\text { FGD-UER- } \\
\text { CM-F-01 }\end{array}$ & 10 & Female & $23-50$ & None-secondary & $\begin{array}{l}\text { Relatives and } \\
\text { friends. }\end{array}$ & 75.45 & \multirow{4}{*}{\multicolumn{2}{|c|}{ Upper East Region (UER) }} \\
\hline $\begin{array}{l}\text { FGD-UER- } \\
\text { CM-F-02 }\end{array}$ & 11 & Female & $30-60$ & None-secondary & $\begin{array}{l}\text { Relatives, } \\
\text { friends. }\end{array}$ & 60.23 & & \\
\hline $\begin{array}{l}\text { FGD-UER- } \\
\text { CM-M-01 }\end{array}$ & 8 & Male & $23-60$ & None-secondary & $\begin{array}{l}\text { Relatives and } \\
\text { friends. }\end{array}$ & 63.45 & & \\
\hline $\begin{array}{l}\text { FGD-UER- } \\
\text { CM-M-02 }\end{array}$ & 9 & Male & $20-61$ & None-tertiary & $\begin{array}{l}\text { Relatives, } \\
\text { community } \\
\text { members and } \\
\text { friends. }\end{array}$ & 72.36 & & \\
\hline $\begin{array}{l}\text { FGD-NR- } \\
\text { CM-F-01 }\end{array}$ & 12 & Female & $20-62$ & None-primary & $\begin{array}{l}\text { Relatives, } \\
\text { community } \\
\text { members and } \\
\text { friends. }\end{array}$ & 71.52 & \multirow{4}{*}{\multicolumn{2}{|c|}{ Northern Region (NR) }} \\
\hline $\begin{array}{l}\text { FGD-NR- } \\
\text { CM-F-02 }\end{array}$ & 11 & Female & $19-55$ & None-secondary & $\begin{array}{l}\text { Relatives, } \\
\text { community } \\
\text { members and } \\
\text { friends. }\end{array}$ & 68.25 & & \\
\hline $\begin{array}{l}\text { FGD-NR- } \\
\text { CM-M-01 }\end{array}$ & 10 & Male & $20-67$ & None-tertiary & $\begin{array}{l}\text { Relatives, } \\
\text { community } \\
\text { members and } \\
\text { friends. }\end{array}$ & 59.84 & & \\
\hline $\begin{array}{l}\text { FGD-NR- } \\
\text { CM-M-02 }\end{array}$ & 9 & Male & $18-65$ & None-secondary & $\begin{array}{l}\text { Relatives, } \\
\text { community } \\
\text { members and } \\
\text { friends. }\end{array}$ & 72.21 & & \\
\hline \multicolumn{9}{|c|}{ B: Characteristics of semi-structured indepth interviews (IDIs) with community leaders (CLs) (n=16) } \\
\hline ID & $\begin{array}{l}\text { No. of interviews } \\
\text { conducted }\end{array}$ & Sex & $\begin{array}{l}\text { Age } \\
\text { range (years) }\end{array}$ & $\begin{array}{l}\text { Educational } \\
\text { status }\end{array}$ & $\begin{array}{l}\text { Position in } \\
\text { community }\end{array}$ & $\begin{array}{l}\text { Known } \\
\text { someone } \\
\text { diagnosed with } \\
\text { HTN }\end{array}$ & Duration (mm) & Location \\
\hline IDIs-UER-CL-F & 1 & Female & 45 & Primary & $\begin{array}{l}\text { Women's leader/ } \\
\text { chief's wife. }\end{array}$ & Relative & 33.12 & UER \\
\hline IDIs-UER-CL-M & 7 & Male & $48-63$ & None-tertiary & $\begin{array}{l}\text { Chiefs, youth } \\
\text { leaders and } \\
\text { assemblymen. }\end{array}$ & $\begin{array}{l}\text { Relatives, } \\
\text { community } \\
\text { members and } \\
\text { friends. }\end{array}$ & $30.11-55.69$ & \\
\hline IDIs-NR-CL-F & 2 & Female & $48-52$ & None & Women leaders. & $\begin{array}{l}\text { Relatives, } \\
\text { community } \\
\text { members and } \\
\text { friends. }\end{array}$ & $35.22-60.69$ & NR \\
\hline IDIs-NR-CL-M & 6 & Male & $50-68$ & None-tertiary & $\begin{array}{l}\text { Chiefs, youth } \\
\text { leaders and } \\
\text { assemblymen. }\end{array}$ & $\begin{array}{l}\text { Relatives, } \\
\text { community } \\
\text { members and } \\
\text { friends. }\end{array}$ & $33.12-46.25$ & \\
\hline
\end{tabular}

body fluids such as saliva of a person with HTN. Dizziness, headaches, body pains, blurred vision and body weakness were perceived to be signs of HTN.

[Z] eemzore ba-a [blood is plenty]...that is what they [health workers] say. This sickness when you have it, nothing shows [un] like when you get malaria.the blood is plenty in your body and you have to go and remove some [of it]...it is a sickness that makes ones blood not to flow the normal way like the veins are blocked like something like oil or dirt is blocking them... if a person who has too much blood drinks from a cup and his saliva remains on the cup and you also take the same cup and drink from it, then you will also get the sickness...I don't think people think they can get the blood is plenty like that [laughing]. FGD-UER-CM-M-03

They say it is called 'Zhiduli [blood is gone high]'... it is when you have too much blood in you and when your eyes turn [dizziness]. IDI-NR-CL-M-06

In UER especially, persons with HTN were perceived by community members as sicklers (people who frequently get sick) or regarded as alcoholics. Some community members also perceived HTN as witchcraft and/or spiritual attacks. This was substantiated by community leaders who explained that these beliefs resulted from 
persons with HTN suddenly falling sick, always been sick and/or weak and/or arouse from the unexpected deaths of people who developed HTN. Unexpected deaths of persons with HTN were often attributed to them having sought biomedical treatments requiring injections. HTN was therefore perceived as 'not a hospital disease' (not treatable biomedical).

Some too say the sunsua ba is not a hospital sickness and if they go and they [health workers] inject them, they will die... they are just sicklers or they have sickness in their bodies. FGD-UER-CM-F-04

When someone is being attacked by zeemzore ba-a, you know it can cause someone to die suddenly. When it happens like that, community or local people think that it is witchcraft or something like that. They look at how the person has died and they conclude that maybe someone might have done something. IDI-UER-CL-05

\section{Sources of information on HTN}

Community members explained that unless they went to the health facility, could read in English or had a relative or friend with HTN, they had little information about HTN and how to prevent it, resulting in many community members developing HTN. Community leaders attributed the lack of information on HTN to community members' inability to read in English or in the local languages that they explained, limits their access to information on HTN. Community members explained that their main sources of information on HTN were through television, radio and information vans. Other sources of information mentioned by community leaders but not by members were occasional free health screening exercises organised by churches and non-governmental organisations.

We actually don't know much about this disease and what it can do... I have heard people died suddenly of too much blood in their body... So, the deaths of people and on the radio that I hear information about that too much blood in the body. FGD-UER-CM-M-03

It attacked my senior brother and I took care of him until he passed on... we have been hearing it through FM stations... We have information van that sometimes goes round to talk about those sicknesses because some of them can't sit by radio or can't get signal of FM to be able to hear such talks... And in the hospital, we get information about it. FGD-NR-CM-M-02

\section{Causes of HTN}

Participants held the opinion that 'unhealthy food' (oily, fatty, salty, sugary and spicy food) is the main cause of HTN in their communities. They explained that while the use of local spices like dawadawa (fermented African locust beans) perceived as healthier had been neglected, foreign spices containing chemicals regarded as unhealthy are mainly used in food preparation nowadays. The use of chemicals in growing and preserving food crops, the consumption of unhealthy food, snuff (a smokeless tobacco) and kolanuts (a local caffeine-containing fruit) were all perceived as causing HTN. Excessive alcohol intake especially of the locally brewed alcoholic drinks and products such as pito (alcoholic beverage made from fermented millet or sorghum), Adonko bitters and Akpeteshie (alcoholic beverage and spirits) were perceived by participants as causes of HTN. Chewing kolanuts and sniffing snuff was reportedly commonly consumed and perceived by community members to cause HTN, but this was not mentioned by community leaders.

$[\mathrm{N}]$ ot eating the food we are supposed to be eating and engaging in hard work more than our strength and the heat [weather]. [T] hey also want salty and sugary foods which is the cause of the sickness now... nowadays they use magi in cooking and the different types of magi is what is causing the sickness plenty now... they don't allow the magi to boil well when cooking. FGD-UER-CM-M-01

What causes it is from the food and drinks especially alcohol, taking too much of it can cause it... most of the young men will go to drink pito and they will end up adding Adonko bitters including the kola and snuff and with the snuff they share it with their colleagues and all these are giving the sickness.... FGD-UER-CM-F-04

Another major perceived cause of HTN was the experience of extreme emotions such as sadness, panic, fright and shock due to traumatic events. Community members recounted stories where community members developed HTN due to the unexpected death of a child, friend or relative or from receiving bad news. Poverty, which community members considered as pervasive in their communities and the experience of traumatic events were explained to cause stress, excessive worrying or overthinking and anguish which led to the development of HTN. This was confirmed by community leaders. Other less commonly perceived causes of HTN reported by community members but not by community leaders included dirt, smoking, excessive hard work and the hot weather. In NR particularly, members added that health workers often attributed HTN with tensions within their polygamous families.

... if you become too frightened that also can lead to Zhiduli... something bad happens to you, it can bring about the Zhimdoro... we heard one of us passed on [died] and it was that her baby died mysteriously. So her heart was spoilt [heartbroken]. It was not up to two months when that sickness [hypertension] attacked that woman and she died... FGD-NR-CM-F-01

[I]t is also caused by too much thinking that can make your heart sick such that any loud sound around you, makes you panic... when one can't cater for the needs of the family, you think a lot and panic begins to set into your life which can cause blood to 
go high... poverty and hunger can cause the blood to go high, we work a lot and yet we don't feed well... poverty! When you find it difficult to feed and cater for the children especially pay their fees, you will fall sick, because you think a lot... which can cause your blood to go high. FGD-UER-CM-F-01

\section{Comparing current HTN occurrence with past occurrence}

Participants held the view that HTN was more common currently compared with the past, when HTN was rare in their communities. Community members recounted that when they were younger (10-15years ago), HTN was perceived to be an illness that attacked the rich and affluent but currently, HTN attacks any person regardless of socioeconomic status. Community members attributed the increasing prevalence to changes in diet and overthinking about increasing costs of living, and fewer economic opportunities that caused stress and excessive thinking. They further explained that in the past, they could farm and had fewer needs, but currently due to modernisation and urbanisation, most people had lost their farmlands and jobs and had more needs such as school fees for children and medical bills to pay that caused them be stressed.

... if you look at first [past] and now, people used not to think a lot like now; where any young person would start thinking about how to acquire property, school fees and work and this is what is causing the disease now more than the past... it was not like that when we were young. if you look at those days [past], families used to cook with dawadawa, but nowadays they use magi in cooking and the different magi is what is causing the diseases now... FGD-UER-CM-M-01

... the zeemzore ba is as a result of the numerous problems we have nowadays. Some time back, people used not to die so much. It was rare when we were small... it's very common nowadays at the hospital. FGD-NR-CM-F-03

\section{Current treatment options}

We found three key themes, namely biomedical care, traditional remedies and medicines, and concurrent use of traditional remedies and medicines and biomedical treatments.

\section{Biomedical care}

Biomedical care was perceived by community members as best for diagnosing HTN, providing quick relief from pain and managing perceived HTN related symptoms such as headaches, dizziness, body pains or weakness. This view was confirmed by community leaders who explained that when members got these perceived HTN-related symptoms, they were first rushed to the nearest health facility for diagnosis and treatment, while traditional medicine was usually used for curing HTN after diagnosis at the health facility.
$[\mathrm{T}]$ he truth is when blood becomes plenty, you get dizzy and headache and can even fall down so you have to go to the hospital to get their medicine so that the head and the dizziness will go [away] but it doesn't cure the sickness... like my sister said, some even fall down so we take to the hospital and the nurse will tell us it is the blood that has gone high and give medicine so that they will not be falling down like that again... as for the hospital, if you don't go, how will you know it is your blood that is doing that? The traditional medicine will not know it is the blood. So you have to go to hospital and after that we now go and greet the Dagbani medicine so that it [hypertension] will go away [cured]. FGD-NR-CM-F-01

Like my brother has said, the way this sickness is, if you don't get the hospital medicine you will suffer [pain] for long because the traditional medicine does not make the suffering go away but it will cure it. Just that it will take time so you need the hospital medicine to help you with the suffering, you see what I mean? That suffering is too much that you need those medicines. FGD-UER-CM-M-03

Community members held the view that non-adherence to antihypertensive medication was due to reasons such as poverty and inability to pay for medicines, inability to swallow, the belief that traditional medicine can cure HTN and the perception that taking antihypertensive medicines over a long period can lead to the development of other diseases. Side effects of medication such as sexual and body weakness were also mentioned by community members and leaders in NR as key reasons for male non-adherence to medication. Distrust in antihypertensive medication and the feeling that HTN was controlled were key reasons for none adherence to medication mentioned by community members and leaders in UER.

[S] ome people take the medicine and when they are better they will stop... some too they will be taking the medicine and when they hear that this or that traditional medicine cures it like they always hear in the radio or at the market, they will stop the hospital medicine and do the traditional treatment... my sister, this sickness is not a hospital diseases so you take the medicine small and stop and do your traditional medicine and the sickness will be finished... You cannot be taking medicine till you die... I hear if you take it [antihypertensive] too long, you will get another sickness... But this sickness too err, why will you be taking medicine like that all the time? FGD-NR-CM-M-04

A lot, a lot, people have been saying a lot about er$\mathrm{r}$ (laugh)... it makes you weak... You know some people, even some people take it to be family planning [sexual weakness] so... they don't want to take the drugs. IDI-NR-CL-M-01 
Community leaders in UER added that certain cultural practices involving alcohol intake and eating specific traditional foods during specific social events were key reasons for none adherence to dietary and other behavioural modification recommendations. Members added that the attitudes of health professionals, inadequate sensitisation on HTN by health workers and frequent stock outs of antihypertension medication at health facilities were reasons why community members with HTN were unable to manage their condition adequately,

... in the case where you have lost your father or mother and they are performing the funeral... there's always drink and food err for you the children which you must take. You cannot say that you would not take because you have hypertension and they [health workers] say you should eat or drink. If you refuse to take, they will say maybe you have a hand in the person's death... IDI-UER-CL-05

\section{Traditional and alternative medicines and remedies}

Community members held the view that chewing kolanuts manages HTN but traditional medicines provide a complete cure for HTN. They explained that dawadawa is the main ingredient used in various ways or collectively with other herbal medicines for curing HTN depending on the traditional healer and severity of illness. They elaborated that dawadawa could be eaten as a cooked meal, grounded and mixed as pomade for the body or mixed with water for drinking or for bathing as part of traditional medicines for curing HTN. Community members explained that the traditional healer identifies and provides the herbs, barks or roots that are then prepared and ground into flour that is mixed with oil and rubbed on the body of the person or mixed with water for bathing. Treatment continues until the herbalist or healer says HTN was cured. Community leaders confirmed this and added that access to and payment for treatment involved the provision of a new calabash and fowls determined by the sex of the patient, that is, three and four fowls for male and female, respectively. While use of dawadawa for traditional treatment was more commonly reported in NR, the use of herbs, barks of trees and roots for traditional medicines was more commonly reported in UER.

We have seen that the Dagbani medicine (traditional medicine) is better because, I have never seen anybody suffering from that sickness and after many visits to the hospital he/she [person with hypertension] has been cured rather it would be in him/her until it kills him/her. But with our medicine [traditional], we have been seeing them been treated and they become cured... The treatment is just 'err' the Dawadawa. The Zilinbong is what they use to rub him/her for the leg or hand to wake up. Then they would stop the medicine [antihypertensive] and using the Dawadawa alone in cooking for him/her to be eating... or you grind it and prepare tea for the person to drink, the blood will go down. It can cure the sickness... they would go to the bush and fetch the herbs home and put the leaves on fire. Then when it boils, then they would bring it down and allow it to get cooled. Then they would use it to be massaging his/her body part with the sickness [stroke].

That also can cure it... FGD-NR-CM-F-01

\section{Concurrent use of biomedical and traditional and alternative} medicines and remedies

Concurrent use of both traditional medicines and antihypertensive medicines were perceived to be frequent and encouraged by community members. They held the belief that concurrent use could also cure HTN and reported that health professionals did not discourage them from concurrent use. Members elaborated that antihypertensive medicines were effective at providing quick relief from perceived HTN related symptoms, while traditional treatments were perceived as the most effective treatment for completely curing HTN. HTN was particularly completely curable if traditional medicine was used prior to getting injections (biomedical treatment) or if HTN was not 'severe' (had not progressed to stroke or hospitalisation). Chewing kolanuts were also reportedly commonly used in managing HTN when using antihypertensive medication and/or traditional medicine. Community leaders confirmed these perceptions and explained that community members often sought biomedical care first to diagnose HTN prior to seeking traditional medicine for cure. Participants recounted numerous herbal medicines advertised on TV or radio and at their marketplaces using information vans or public address systems that reported the ability to cure HTN. The belief in a complete cure for HTN using traditional treatment was more commonly reported in NR compared with UER.

Others seek traditional treatment and many people now use that. Like they chew the 'guure' (kolanuts) too. People always say in the market that their medicine can cure hypertension, sugar disease, HIV AIDS but some too go to the hospital for the medicine... when you get the medicine [antihypertensive], you take in the morning or evening, you take and then you look for the one that treats it our way [traditionally] and you will take it too. They [health professionals] did not say we should not take both hospital medicine and local medicine... you can even take their medicine and chew your kola and it will go. FGD-UER-CM-M-01

You have to keep trying both. The nurses don't say we should not try so you have to do the two and see. Maybe one in the morning and the other one when you are going to sleep. the way I see it, there is not one way to get good health so you can take the hospital medicine so that the pain will go [away] and then you chew the kola and do the traditional medicine to cure it... You can do the two so that they will work together to cure you. FGD-NR-CM-M-04 


\section{Community support for people living with HTN}

Participants held the opinion that social support was important for persons with HTN during treatment. They elaborated that family and community members provide assistance in the needed dietary and behavioural changes while ensuring that treatment was adhered to. They reported an absence of HTN-related stigma in their communities but added that some persons with HTN did not want community or family members to know about their sickness and this hindered community and family members' ability to support them in treatment and management. Leaders added that the lack of information on HTN and its causes, how to manage it and how to support friends and relatives with HTN were key obstacles to members' ability to provide adequate social support.

Some people with BP will not tell others about it even if you are in the same house with them... it's not like we will leave you alone too [stigma] but since they don't want people to know about their illness, how can we help them?... The person needs money to go to the hospital and you don't have the money to help the person to go... it might happen that the doctor says the person shouldn't eat certain foods but you can't afford to buy such ingredients to cook the food... FGD-UER-CM-F-04

You know if you have this sickness and you are doing the Dagbani medicine, your family have to help you to cook the medicine and help you to drink it... when my brother had it, I had to always rub the medicine on his body after he bathes... If you family is not there, who will be taking you to hospital to collect those plenty medicines? Who will ask you if you have taken your medicine? Or even cook for you? Even when they are talking to you and you are happy it helps you. The healers always say the family should not make the person angry but make the person heart to lie down [calm]. FGD-NR-CM-M-02

Furthermore, community leaders expounded that members' inability to read or write in English or the local languages was a key barrier to accessing HTN-related information that hinders their ability to provided adequate social support for persons with HTN. They also explained that social support was poor because some community and family members get frustrated with the inability of some persons with HTN to comply with behavioural changes such as reducing their consumption of alcohol and/or engaged in surreptitious use of salt. Community members also indicated that the relationships between a person with HTN and other family and community members also determined the level and kind of social support that persons with HTN received. As such, members with HTN who were reportedly active and/or had good relations with community and family received social support in the form of financial donations, social visits and encouragement. Other key barriers to proving social support for persons with HTN that community members mentioned included poverty and working demands of family members, which made it difficult to encourage adherence to dietary recommendations, provide transport costs and assist persons with HTN to attend the health facilities for routine health monitoring and refill of medicines.

... one will get up in the morning and instead of cooking good food for the person to reduce the blood, they will just rush to work and may be come back in the evening and now prepare food for the person...if the patient is advised not to do certain things like the drink and the person is still does, it becomes very annoying to the people who help him and so they will leave him completely to do what he wants... it depends on how the person relates with his friends or the members of the church and the others, that may be prevent them from supporting him. FGD-UER-CM-M-03

You cook and don't put salt for the person and the person will hide and put salt or fetch the soup from the pot [separate pot of food with salt] for the other people. That one too has salt... my mother used to do that. We talked but she will not listen. We too have to eat our food with salt because we don't have it [hypertension]... You cook and separate his food and not put salt in his and he will tell you the food is not sweet and go out and eat somewhere. If you joke he will even bring another woman because you cook tasteless food for him [laughter]... Even most of the food, we dry [preserve] with the salt so what can you do? You ask your husband if he has taken the medicine and he shouts at you. You also don't know what to do to help them. We haven't gone to school. FGD-NR-CM-F-03

Leaders said despite the inadequate information that community members had regarding HTN, they encourage and advice members to support persons with HTN to adhere to treatment whether traditional or biomedical and dietary advice. They held the view that family and community members could support their relatives and/ or friends with HTN by reminding them to take medication or assisting them during traditional treatment. They mentioned ensuring adherence to dietary advice by cooking separate salt free dishes for persons with HTN since other family members eat salt.

I don't think people have that information on it and how to help them except that when those who knows about it comes to hear of someone having it, then they can help in terms of the telling the persons about food they should be eating and what they cannot do or fetching their food separate in a different pot for them before adding salt. Because one person does not eat salt should the rest of us too not eat it? No. So you separate the food. IDI-UER-CL-04 


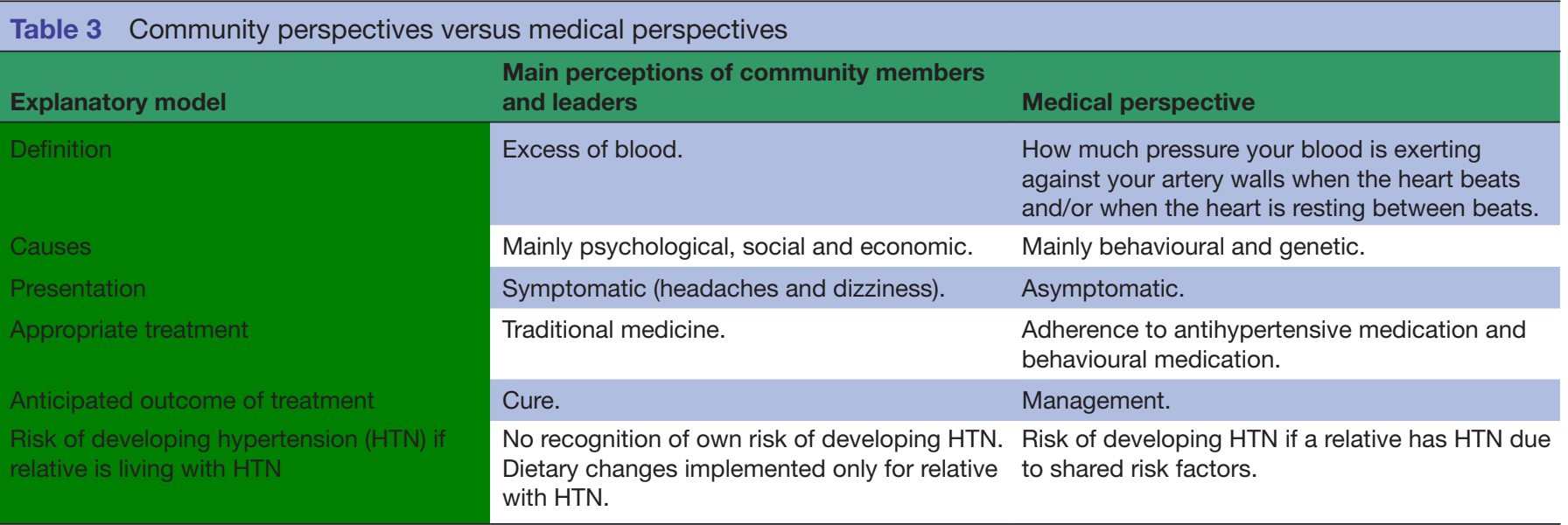

Community members emphasised the need for health workers to provide communities with information on the causes of HTN, how they can prevent and manage HTN and how they can support to persons with HTN to better manage their condition. They recommended identifying and forming peer support groups for people with HTN.

$[\mathrm{T}]$ hey should come together and announce in the communities that those who have this illness will come so that they can help each other like a group or write to an NGO to help, since some people don't have the money to cater for the illness and the NGO can buy the BP machine for the community and they will be checking their blood and also providing them with the drugs for the sickness. FGD-UER-CM-F-04

\section{DISCUSSION}

\section{Summary of findings}

This study provides in-depth insights on community lay perceptions regarding HTN and its treatment in four rural communities in northern Ghana, a relative grey area of research. It explores the broader sociocultural and structural factors that influence patient behaviour and practices particularly in rural areas. While participants had similar EMs, there are differences between community EMs and medical EMs (table 3). The results suggest that sociocultural norms, economic factors and prevailing healthcare options have a strong influence on how communities' conceptualise and construct meanings for HTN. They also show how collective processes and structural factors shape sociocultural norms and unravel how these norms influence communities' health-seeking behaviour and influence the choice and utilisation of treatment options for HTN at the community and individual levels. These findings provide key evidence that highlight the need for a public health approach to HTN control in order to make sustained gains in treatment and control. We use the findings presented in table 3 to guide the discussions in the subheadings, comparison with previous literature and the implications for clinical practice, policy and future research.

\section{Comparison with previous literature}

We found commonalities in lay perceptions and medical understanding regarding diet and experience of traumatic events as causes of HTN and the attribution of these changes to modernisation that is similar to findings of a study conducted among persons with HTN in southern Ghana. ${ }^{40}$ Other perceived causes of HTN in line with other studies on HTN among Africans included chewing kola nuts, use of snuff and stress resulting from socioeconomic situations and excessive alcohol consumption. ${ }^{14-16}$ 40-42 Contrary to the medical EMs for HTN, communities perceive HTN as an 'excess of blood or too much blood' in a person and/or a spiritual or witchcraft attack, which is similar to findings of studies conducted in southern Ghana and urban Tanzania. ${ }^{22} 4042$ In this predominantly rural area, these perceptions are potentially facilitated by the low literacy rates for adults 15 years and above, which limits access to health information. Given that many community members cannot read or write in English or in the local languages, access to health information is mainly through spoken local language via contact with health workers and through radio and television programmes conducted in the local languages. For example, the perception that HTN is 'excess blood' is facilitated partly by how HTN is translated by health professionals to community members into the local languages. Findings from our earlier study in northern Ghana show that health professionals held the opinion that because of translation difficulties, their translation of HTN into the local languages may have contributed to the perception that HTN is 'excess of blood (Nyaaba, unpublished). Health professionals therefore need to address this translation difficulty and provide succinct public education in the communities to enhance communities understanding of HTN and its causes in order to counter this perception.

In addition, while biomedical care is sought for diagnosing and providing quick relief from pain and perceived HTN related symptoms, there appears to be a psychosocial inclination towards seeking traditional and alternative treatments that promise a complete cure for 
HTN. Various studies have suggested that healer shopping is a prevailing response for both communicable and NCDs in southern and northern Ghana ${ }^{22434}$ and in other African countries. ${ }^{154-46}$ A recent study on healer shopping for diabetes in southern Ghana found that despite a preference for biomedical medication, the psychosocial and socioeconomic impacts of diabetes promote a cure seeking behaviour in patients with diabetes and medical inaction that potentially aggravate complications of diabetes. ${ }^{22}$ Another study conducted in Zambia also found a preference for traditional and alternative treatment for HTN among rural community members. ${ }^{15}$ While perceived symptoms of HTN could potentially discourage adherence to antihypertensive medication based on their absence, non-adherence to antihypertensive medication as explored within our study was reportedly due to reasons such as side effects, denial of condition and limited access to medication, which are similar to findings of other studies on HTN and other chronic diseases conducted among Ghanaians. ${ }^{5} 122247$ Another barrier to medication adherence and subsequently HTN control is the fear that taking antihypertensive medication for a long period can lead to the development of other diseases. Health interventions therefore need to take these perceptions into consideration in designing innovative health literacy programmes that effectively dispel these beliefs to improve health behavioural practices towards effective HTN control.

Furthermore, the perception that HTN is not a hospital disease differs considerably from the medical EMs of HTN, which considers HTN as a chronic condition best treated with adherence to antihypertensive medication and behaviour modification. This perception facilitates and is facilitated by the perception that HTN is curable using traditional treatment if traditional treatment is sought prior to biomedical care. These perceptions possibly motivate the concurrent use of traditional medicines and antihypertensive medicines that can potentially lead to uncontrolled HTN and its related complications. It also appears that while there are concerns on interactions arising from concurrent use of antihypertensive medication and traditional medicines, these concerns appear averted by using the different treatments at different times of a day or periods. These perceptions are enabled by the numerous herbal medicines that promise cure for HTN and other chronic conditions advertised via television, radio and information vans, which are the main sources of information in these rural communities.

It also appears that while there is a common recognition from our study that social support could contribute to improve compliance to dietary regimes and medication adherence, there are socioeconomic and other structural barriers that impede family and community members' ability to adequately support people with HTN. Studies have shown that social support contributes significantly to improving health outcomes. ${ }^{48}$ The results show that sociocultural and economic factors hinder social support and a person's own social relations with family and/or community members determine, to an extent, the social support that he or she receives. Persons with HTN therefore have to manage these sociocultural dynamics within their families and communities to enable them receive social support for their condition. In addition, despite implementing dietary changes such as reduction in salt intake or consumption of fatty foods for a relative with HTN, these are specifically for the hypertensive relative and not for non-hypertensive family members as they did not recognise their own risk of developing HTN. Similar findings were made in a study conducted in southern Ghana where despite individuals' awareness of HTN, individuals did not consider themselves at risk of developing HTN. ${ }^{18}$ The situation is worsened by the fact that high levels of illiteracy and poverty hinder community and family members' access to information on HTN. Family members could potentially play a big role in HTN control by ensuring adherence to medication and creating a conducive environment for persons with HTN if they empowered with information.

Lastly, the findings suggest that structural factors such as difficulties in communication, poverty and inadequate access to information are recognised by community members as key factors that hinder their ability to manage HTN. Together with high illiteracy rates recorded in such rural settings, these structural factors hinder communities' and patients' understanding of the causes of HTN and indeed other chronic conditions and also hinder effective control efforts as they contribute to perpetuate perceptions regarding treatment and how to manage such chronic conditions.

\section{Implications for clinical practice, policy and future research}

The findings have several important implications for HTN control. First, marked differences exist between communities' EMs and medical EMs of HTN and its treatment that could influence patients' behavioural practices and potentially contribute to the poor control of HTN. It is apparent that these perceptions are influenced and shaped by sociocultural norms, economic factors such as education and literacy and health worker challenges in communication. As these structural and cultural factors influence how communities understand and conceptualise HTN and construct their EMs regarding HTN and its treatment, they present key obstacles to improving HTN treatment and control. For example, while the perception that HTN is excess blood could lead to the avoidance of protein-rich diets in a bid to reduce blood and causing anaemia and malnutrition, the perception that persons with HTN are 'sicklers' or alcoholics could lead to stigma and poor social support for such persons and subsequently affect HTN control. Clinicians and health policy makers, therefore, need to understand and consider how communities develop these perceptions in designing social and culturally acceptable public health campaigns and interventions to provide succinct public education to dispel these perceptions and contribute to HTN control particularly in rural communities. 
The fear that taking antihypertensive medicines for long periods can lead to the development of other diseases deserves attention as it differs from the medical model. If this is not addressed, it could lead to uncontrolled HTN and the development of HTN-related complications because HTN is a risk factor for CVDs. The impacts and consequences of uncontrolled HTN on individuals, communities and the health system would be worsened. Clinicians and policymakers therefore need to design innovative health literacy programmes that effectively counter these beliefs and improve adherence to medication.

Furthermore, the finding that the use of local stimulants such as the chewing of specific types of kolanuts can manage HTN is significantly important as chewing kolanuts is considered a sign of ageing, woven into the sociocultural fabric of most rural communities in northern Ghana and thus persons with HTN who chew kola may be less adherent to medication because they believe they are already managing their condition by chewing kolanuts. While this has received little attention in current HTN literature, further evidence is needed to explore if patients hold this perception and practice it and how it contributes to HTN control.

Importantly, the perception that traditional medicine can completely cure HTN and the herbal medicines that promise cure for HTN deserves attention as it contributes to the poor control of HTN and the growing NCD burden in the country. It epitomises the low focus on NCDs in healthcare systems in low and middle-income countries (LMICs) and calls for the significant structural and policy reforms to address the increasing NCD prevalence and poor control particularly for HTN. While the Traditional and Alternative Medicines (TAM) unit was established by the Ministry of Health $(\mathrm{MoH})$ to provide herbal medical care and regulate herbal and alternative medicines in Ghana, it appears that the TAM unit needs to put more efforts into identifying and regulating herbal medicine advertisements and use. Such advertisements of herbal medicines promising cures for HTN and related sequelae in the media space and in the market areas need to be carefully monitored and regulated. Effective collaboration with the National Media Commission and its media houses could potentially contribute to regulating these adverts in the media space and contribute to improving community perceptions surrounding HTN and its treatment.

Moreover, the finding that concurrent use of antihypertensive medication and traditional remedies and medicines is encouraged and could cure HTN deserves attention. While further research is needed to identify the specific implications of concurrent use of these treatments, it could possibly aggravate HTN and its related complications. This, coupled with the perception that HTN can be cured using traditional medicines if sought prior to biomedical care, presents serious obstacles to effective HTN control as they facilitate delays in seeking healthcare for early diagnosis and could affect adherence to medication and dietary changes. These deserve urgent health policy attention particularly as they have received little attention in current HTN literature.

In addition, the finding that community members do not recognise their own risk of developing HTN even when a relative is hypertensive warrants attention as it is precisely because a relative has HTN that family members need to be vigilant about risk and adapt major behavioural changes due to shared risk factors. For instance, while it sounds practical that food for a relative with HTN be separated prior to adding salt to the food for other family members, it is important that all family members reduce their intake of salt in order to reduce their risk of HTN. A public health approach to HTN control is therefore needed, which should include empowering communities with health information about HTN including the benefits of implementing dietary and other behavioural changes for the entire family. It should also empower communities on how they can support members with HTN while promoting healthy living. Particularly in rural areas where social and cultural structures are traditionally defined, community members and leaders and family members are major influencers for healthseeking behaviour and adherence and should therefore be involved in the design and implementation of public health campaigns and patient care and self-management interventions.

Finally, these perceptions could potentially arise from and are fuelled by socioeconomic factors such as poverty, limited access to health healthcare and low literacy that predominate in such rural settings and influence healthseeking behaviour. It is evident that these perceptions regarding causes, treatment and social support for HTN are embedded in structural conditions that, together with poor communication, poverty and inadequate access to health information regarding HTN are key underlying causes of these perceptions. The situation is further compounded by cultural factors that facilitate these perceptions and hinder effective control of HTN in such communities. These findings highlight the critical need for a holistic public health approach to HTN control that addresses the fundamental underlying causes of these perceptions while empowering individuals and communities with the needed information in ways that they can understand and use in order to effectively improve HTN control and promote healthy living.

\section{Strengths and limitations of this study}

With regards to limitations, the study collected data from four communities purposively sampled in northern Ghana, which may not reflect the views of other communities or ethnic groups in northern Ghana. To ensure that the results were representative we conducted the study in the main communities at the health system level where HTN care is provided and also used semistructured interviews with community leaders to triangulate and explore in depth the data that was collected in the FGDs. Second, while it would have been ideal to have an equal 
representation of male and female community leaders in the semistructured interviews, this was not possible due to the limited number of actively involved female community leaders who met our selection criteria.

The main strength of this study is that it collected data from community members who had some general and/ or in-depth experience with a person with HTN and thus allowed us to identify community perceptions about HTN and its treatment options, explore the processes and factors that shape these perceptions surrounding HTN and how they differ from current medical knowledge. In addition, to the best of our knowledge, this is the first qualitative study that seeks to provide lay community perceptions surrounding HTN and its treatment in rural northern Ghana. This is crucial to informing the design and implementation of health interventions to improve HTN control and prevent related sequelae and could be applicable to other NCDs.

\section{CONCLUSION}

These findings provide key evidence that underline the need for a public health approach that targets individuals with HTN and health professionals, communities and family members in a bid to improve HTN control and potentially encourage healthy living. Given high levels of poverty and low literacy rates in rural communities in LMICs, there is a need for designing and implementing targeted integrated interventions at various levels (individual, family, community, regional and national levels) with the aim of increasing awareness on HTN and its related complications, promoting healthy living and encouraging social support for people with HTN. Health policy needs to take into consideration these sociocultural and economic peculiarities within differing geographical contexts in adapting and implementing national strategies aimed at reducing the increasing NCD burden and particularly improve HTN control.

Acknowledgements The Erasmus Mundus Joint Doctorate Program of the European Union supports this work though the Amsterdam Institute of Global Health and Development as part of GNN's PhD candidacy at the Academic Medical Centre/ University of Amsterdam. The authors would also like to thank the directors and staff of the regional health directors in the Northern and Upper East Regions for all their support during fieldwork in Ghana. We acknowledge the support received from Dr Briamah Baba Abubakari (Ghana Health Service, Northern Region), Dr Fredrick Boateng (Ghana Health Service, Ashanti Region), Mr Gideon Sarpong (Ashanti Region) and Mr Duncan Adogboba (Ghana Health Service, Upper East Region) during data collection in Ghana. Lastly, we appreciate the efforts of the administrators and staff of the health facilities where we collected field data and thank the community members and leaders who participated in this study.

Contributors GNN, CA, Ad-GA and KS conceived the study idea and designed the study proposal. GNN collected the data, reviewed transcripts, coded, analysed, interpreted the results and developed the manuscript. LM and Ad-GA contributed to refining the study design, designing topic guides for data collection, supervised GNN in data collection and coding, interpreting the results and revising the manuscript. CA and KS contributed to analysing, interpreting, revising and shaping the manuscript. All authors read and approved the final manuscript and are accountable for all aspects of the manuscript.

Funding This work is part of GNN's doctoral studies funded by the Erasmus Mundus Joint Doctorate Program of the European Union Specific Grant Agreement 2015-1595.
Competing interests None declared.

Patient consent Not required.

Ethics approval The study received ethical approval from the Ghana Health Service Ethical Review Services (GHS-ERC) numbered GHS-ERC 09/01/201 and administrative consent from the regional health directorates of the two regions and facility administrators.

Provenance and peer review Not commissioned; externally peer reviewed.

Data sharing statement Data collected for this study are primary data collected at study locations in Ghana with the consent of participants, which is stored in a password-protected folder on the Academic Medical Centre, University of Amsterdam's digital platform. The data analysed during the current study are not publicly available due to identifying information contained in verbatim transcripts but are available from the corresponding author on reasonable request.

Open access This is an open access article distributed in accordance with the Creative Commons Attribution Non Commercial (CC BY-NC 4.0) license, which permits others to distribute, remix, adapt, build upon this work non-commercially, and license their derivative works on different terms, provided the original work is properly cited, appropriate credit is given, any changes made indicated, and the use is non-commercial. See: http://creativecommons.org/licenses/by-nc/4.0/.

\section{REFERENCES}

1. Addo J, Agyemang C, Smeeth L, et al. A review of populationbased studies on hypertension in Ghana. Ghana Med J 2012;46(2 Suppl):4-11.

2. de-Graft Aikins A, Unwin N, Agyemang C, et al. Tackling Africa's chronic disease burden: from the local to the global. Global Health 2010;6:5.

3. WHO. A global brief on hypertension. Silent killer, global public health crisis: World Health Organization, 2013.

4. Agyemang C, Bindraban N, Mairuhu G, et al. Prevalence, awareness, treatment, and control of hypertension among Black Surinamese, South Asian Surinamese and White Dutch in Amsterdam, The Netherlands: the SUNSET study. J Hypertens 2005;23:1971-7.

5. Agyemang C, Bruijnzeels MA, Owusu-Dabo E. Factors associated with hypertension awareness, treatment, and control in Ghana, West Africa. J Hum Hypertens 2006;20:67-71.

6. Agyemang C, Kieft S, Snijder MB, et al. Hypertension control in a large multi-ethnic cohort in Amsterdam, The Netherlands: the HELIUS study. Int J Cardiol 2015;183:180-9.

7. Addo J, Smeeth L, Leon DA. Hypertension in sub-saharan Africa: a systematic review. Hypertension 2007;50:1012-8.

8. Agyemang $\mathrm{C}, \mathrm{Nyaaba} \mathrm{G}$, Beune $\mathrm{E}$, et al. Variations in hypertension awareness, treatment, and control among Ghanaian migrants living in Amsterdam, Berlin, London, and nonmigrant Ghanaians living in rural and urban Ghana - the RODAM study. J Hypertens 2018;36:169-77.

9. de-Graft Aikins A, Kushitor M, Koram K, et al. Chronic noncommunicable diseases and the challenge of universal health coverage: insights from community-based cardiovascular disease research in urban poor communities in Accra, Ghana. BMC Public Health 2014;14:S3

10. Kusuma YS. Perceptions on hypertension among migrants in Delhi, India: a qualitative study. BMC Public Health 2009;9:267.

11. Kleinman A. Patients and healers in the context of culture: an exploration of the borderland between anthropology, medicine, and psychiatry. Univ of California Press, 1980.

12. de Graft Aikins A, Anum A, Agyemang C, et al. Lay representations of chronic diseases in Ghana: implications for primary prevention. Ghana Med J 2012;46:59-68.

13. de-Graft Aikins A, Awuah RB, Pera TA, et al. Explanatory models of diabetes in urban poor communities in Accra, Ghana. Ethn Health 2015;20:391-408.

14. Beune EJ, Haafkens JA, Schuster JS, et al. 'Under pressure': How Ghanaian, African-Surinamese and Dutch patients explain hypertension. J Hum Hypertens 2006;20:946-55.

15. Oelke ND, Rush KL, Goma FM, et al. Understanding perceptions and practices for zambian adults in western province at risk for hypertension: an exploratory descriptive study. Glob J Health Sci 2016;8:248-9.

16. Osuala EO, Oluwatosin AO, Osuala FN, et al. Perceptions and thirst for knowledge regarding hypertension among rural dwellers in isunjaba, imo state, nigeria: a qualitative study. Health 2016;08:1603-15.

17. Bosu WK. A comprehensive review of the policy and programmatic response to chronic non-communicable disease in Ghana. Ghana Med J 2012;46:69-78. 
18. Awuah RB, Anarfi JK, Agyemang C, et al. Prevalence, awareness, treatment and control of hypertension in urban poor communities in Accra, Ghana. J Hypertens 2014;32:1203-10.

19. Ad-G de-GA. chronic non-communicable diseases in ghana.: multidisciplinary perspectives: sub-saharan publishers. 2014.

20. Addo J, Smeeth L, Leon DA. Prevalence, detection, management, and control of hypertension in Ghanaian civil servants. Ethn Dis 2008;18:505-11.

21. Agyemang C. Rural and urban differences in blood pressure and hypertension in Ghana, West Africa. Public Health 2006;120:525-33.

22. de-Graft Aikins A. Healer shopping in Africa: new evidence from rural-urban qualitative study of Ghanaian diabetes experiences. BMJ 2005;331:737.

23. Kunutsor S, Powles J. Descriptive epidemiology of blood pressure in a rural adult population in Northern Ghana. Rural Remote Health 2009;9:1095.

24. Region Rhdue. Annual report. 2015:88.

25. SERVICES NRH. 2015 Annual report: ghana health service. 2015:206

26. Edgar Cooke SHaAM. The ghana poverty and inequality report: using the 6th ghana living standards survey. 2016;38.

27. Service GS. Poverty profile in Ghana 2005-2013. 77: Ghana: Ghana Statistical Service, 2014.

28. Hill Z, Kendall C, Arthur P, et al. Recognizing childhood illnesses and their traditional explanations: exploring options for care-seeking interventions in the context of the IMCl strategy in rural Ghana. Trop Med Int Health 2003;8:668-76.

29. Allotey P, Reidpath D. Establishing the causes of childhood mortality in Ghana: the 'spirit child'. Soc Sci Med 2001;52:1007-12.

30. Adongo PB, Kirkwood B, Kendall C. How local community knowledge about malaria affects insecticide-treated net use in northern Ghana. Trop Med Int Health 2005;10:366-78.

31. Gyapong M, Gyapong JO, Adjei S, et al. Filariasis in northern Ghana: some cultural beliefs and practices and their implications for disease control. Soc Sci Med 1996;43:235-42.

32. Janzen JM. Lemba, 1650-1930: a drum of affliction in Africa and the New World: Garland Publishing, Inc., 1982.
33. Glaser BG, Strauss AL. Discovery of grounded theory. Routledge: Strategies for qualitative research, 2017.

34. Walker D, Myrick F. Grounded theory: an exploration of process and procedure. Qual Health Res 2006;16:547-59.

35. Asobayire A, Barley R. Women's cultural perceptions and attitudes towards breast cancer: Northern Ghana. Health Promot Int 2015;30:647-57.

36. Morgan DL. Focus groups as qualitative research: Sage publications, 1996.

37. Krueger RA. Focus groups: A practical guide for applied research: Sage publications, 2014.

38. Dawson S, Manderson L, Tallo VL. A manual for the use of focus groups. 1993.

39. Aikins AD. Living with diabetes in rural and urban Ghana: a critical social psychological examination of illness action and scope for intervention. J Health Psychol 2003;8:557-72.

40. Spencer J, Phillips E, Ogedegbe G. Knowledge, attitudes, beliefs, and blood pressure control in a community-based sample in Ghana. Ethn Dis 2005;15:748.

41. de-Graft Aikins A. Ghana's neglected chronic disease epidemic: a developmental challenge. Ghana Med J 2007;41:154.

42. Strahl $\mathrm{H}$. Cultural interpretations of an emerging health problem: blood pressure in Dar es Salaam, Tanzania. Anthropol Med 2003;10:309-24.

43. Kirby JP. The Islamic dialogue with African traditional religion: divination and health care. Soc Sci Med 1993;36:237-47.

44. Farnes CM. Healer shopping among childbearing women of Ghana, West Africa: Brigham Young University. College of Nursing, 2009.

45. Green EC, disease S. Ethnomedicine and health policy in Africa. Social Science \& Med 1992;35:121-30.

46. Nkwi PN. Perceptions and treatment of diarrhoeal diseases in Cameroon. J Diarrhoeal Dis Res 1994;12:35-41.

47. Beune EJ, Haafkens JA, Agyemang C, et al. How Ghanaian, African-Surinamese and Dutch patients perceive and manage antihypertensive drug treatment: a qualitative study. $J$ Hypertens 2008;26:648-56.

48. Berkman LF. Social support, social networks, social cohesion and health. Soc Work Health Care 2000;31:3-14. 